\title{
LA INVENCIÓN DEL LAZARILLO epistemología y metafísica de la expresión literaria
}

\author{
ESTHER ZARZO
}

Universidad de Alicante

LeÓn Moreno, Como fiel amante o la invención del Lazarillo, Turpin Editores, España [sic, pero Madrid], 2012, 170 págs.

Como fiel amante o la invención del Lazarillo es la última novela de Daniel-Henry Pageaux, conocido catedrático de Littérature comparée de la Sorbona desde 1975. Esta novela se presenta como autobiografía de León Moreno, autor ficcionalizado al que Pageaux cede su lugar en la denominación de Autor y, por tanto, en la consiguiente referencia bibliográfica oficial. Según se podrá comprobar, estamos ante una obra capaz de suscitar una notable problemática de interés teórico y crítico. Se trata de una novela que desde su misma referencia pone en juego algunas de las interrogantes más intrincadas que la autobiografía literaria plantea a la teoría de la ficción, como son la cuestión de la autoría y el problema de la verdad, lo cual, por lo demás, viene a situarla en el núcleo del debate contemporáneo, en torno a la crisis del sujeto y la muerte del autor, además de proyectar muy enriquecedoramente la cuestión del Lazarillo.

El propósito de mi reflexión no es analizar desde el punto de vista narratológico la novela de Pageaux, pues a la discusión acerca de las relaciones entre narración y ficción en el género autobiográfico poco cabe añadir, sino abordar desde la epistemología literaria y la metafísica de la expresión las cuestiones relativas a la naturaleza del sujeto y la referencia sugeridas en esta novela. 
Para ello, me propongo recuperar aquí dos argumentos de carácter teórico fundamentales. En primer término, la fenomenografía de Alfonso Reyes y su análisis de la operación epistemológica propia de la literatura; y en segundo lugar, la metafísica de la expresión de Eduardo Nicol y su ontología del ser simbólico.

Descubriremos así que la novela de Pageaux, con su particular trama de relaciones entre autor, narrador, personaje, escritor, traductor y lector, consigue articular una posibilidad de sentido dialéctico para la autobiografía en un contexto como el actual marcado por el auge de un autobiografísmo difuso y el consecuente escepticismo respecto a la capacidad de la autobiografía para expresar la vida interior.

Así pues, mi exposición se divide en tres partes. Una primera parte descriptiva, en la que se explicita la estructura y argumento de Como fiel amante o la invención del Lazarillo. Una segunda parte teórica, en la que se exponen sintéticamente los conceptos elaborados por Alfonso Reyes y Eduardo Nicol susceptibles de aplicación a nuestro objeto. Y por último, una tercera parte aplicativa en la que nuestra novela se revela como caso paradigmático de tales conceptos.

\section{I}

La estructura general de Como fiel amante o la invención del Lazarillo se edifica sobre la reiteración indefinida de una operación básica: el desplazamiento constante de la primera persona. Pageaux como autor elabora el simulacro autobiográfico de León Moreno, quien a su vez reconstruye el simulacro autobiográfico de Gabriel de Bianos, y así sucesivamente hasta llegar al último simulacro de autobiografía: La vida de Lazarillo de Tormes y de sus fortunas y adversidades. Sobre esta base, Pageaux alterna distintos géneros literarios desde la epístola, al diálogo, a la confesión, a fin de que cada uno de los personajes narre en primera persona su vida. No se trata pues de la típica disposición de la caja china, sino más bien de un descentramiento constante que despliega sentido extensiva e intensivamente gracias a la reproducción clónica de personajes en el tiempo.

Argumentalmente destacan dos autobiografías: la de León Moreno y la de Gabriel de Bianos. León Moreno, el autor ficcionalizado de Como fiel amante, narra el origen, desarrollo y dificultades de su empresa literaria. Una empresa que comienza el día en que Beatriz, amiga de la juventud, aparece de forma inesperada para hacerle un regalo o más bien una petición: que termine el proyecto de su marido, Abel, fallecido un año antes, consistente en reconstruir la vida de un antepasado suyo, Gabriel de Bianos, con el único apoyo de una serie de documentos y cartas tanto personales como literarias escritas en su mayoría en francés. León, catedrático de francés de enseñanza secundaria, que no escritor, tras revisar los documentos con Beatriz acepta la propuesta, Beatriz se marcha y poco tiempo después León recibe la noticia de su muerte. 
En este contexto marcado por la presencia de personas ausentes León relata cómo lleva a cabo la reconstrucción novelesca de la biografía de Gabriel de Bianos, intercalando recuerdos de su vida con Beatriz. Así esboza un tiempo de juventud en el municipio de León, donde junto a Beatriz y Abel forma un triángulo amoroso en el que desempeña el papel de «fiel amante», pues Beatriz escoge a Abel y pasan toda su vida en Francia. Recuerda también el funeral de Abel en Francia. Y por último, la semana que pasa con Beatriz inspeccionando los archivos de Abel en Carboneras (Almería).

Según se ha dicho, llegado el momento de presentar la biografía reconstruida, León Moreno sencillamente cede la palabra a Gabriel de Bianos quien se nos presenta como un joven francés caracterizado por ser un segundón, cuya sustanciosa herencia le permite viajar a lo largo de Francia y España. En la víspera de su viaje formativo hacia Italia en torno a 1520 coincide en Barcelona con doña Elisa de Mendoza, una noble viuda española trece años mayor que él, que regresa de Italia para contraer matrimonio en Toledo. Tras compartir varios días en la misma posada con Elisa y sus acompañantes, el erasmista Fray Juan y el futuro inquisidor don Mateo, Gabriel decide acompañarles en su viaje. Durante el trayecto florece el idilio entre Elisa y Gabriel, y tras una primera etapa en la cual Gabriel escribe de forma autónoma sonetos platonizantes, Elisa le propone a modo de entretenimiento escribir un librillo de manera conjunta. Un libro en el cual, según sus palabras, ante la ruptura anunciada, alumbrar «un hijo del espíritu a falta de otro de carne viva que hubiera alegrado nuestros días [...] una obrita con la que alcanzaremos unos momentos de felicidad y tal vez de eternidad» ${ }^{1}$. Pues bien, este librillo resulta ser el clásico anónimo La vida del Lazarillo de Tormes.

En este punto se explicita una breve poética de la invención. Una técnica italiana que entre Beatriz y Fray Juan enseñan a Gabriel, y que consiste en escribir unas líneas en una cuartilla, plegarla de manera que únicamente se lea un pie de inicio, intercambiarla y repetir la operación. De este modo, en una especie de correspondencia epistolar, Fray Juan y Gabriel por un lado y Beatriz por otro toman el testigo alternativamente en la redacción de una peripecia que sólo conocerán completa al final, o más bien, cuando decidan terminar. Fray Juan es quien guía el talento de Gabriel dándole algunos consejos poéticos para aprovechar «un asunto trivial de la experiencia y transformarlo en materia de arte» ${ }^{2}$, como por ejemplo: determinar un propósito, esbozar un personaje a través del nombre o las condiciones familiares histórico-sociológicas, estructurar el argumento en torno a una complicación, etcétera ${ }^{3}$.

Se percibe claramente una disposición simétrica o más bien clónica. Tenemos de una parte a León Moreno guiado por Abel para cumplir lo prometido a Beatriz; y de otra, a Gabriel aconsejado por Fray Juan para complacer a Elisa.

${ }^{1}$ L. Moreno, Como fiel amante o la invención del Lazarillo, Turpin editores, España, [sic, pero Madrid], 2012, pág. 77.

${ }^{2}$ Cf. L. Moreno, loc. cit., pág. 101.

${ }^{3}$ Cf. L. Moreno, loc. cit., pág. 119. 
Ambos aprendices de escritor guiados y comprometidos en un proyecto literario conjunto.

Poco después del enlace, finaliza el romance y Gabriel se marcha. Un año más tarde, aún lamentando la separación de doña Elisa, y motivado por don Andrés, el emisario de Fray Juan que debía hacerle llegar una copia del Lazarillo, inicia el relato de su vida, y concretamente del viaje con Elisa y su librillo. Una labor que, según le dice don Andrés, le permitirá «encontrar otra vez a [...] Elisa por los caminos que traza la pluma, que han de salir de la fantasía o de la memoria», y que hará de él «otro hombre y nuevo amante, más sensato»».

Continúa la novela con la fortuna del manuscrito del Lazarillo, su pérdida, su recuperación, sus múltiples copias manuscritas e impresas, su persecución religiosa una vez impreso, su ocultación, y demás, complicándose la trama hasta neutralizarse la cronología por repetición de motivos, anacronismos y reproducción clónica de personajes, manuscritos, tiempos y espacios. Sucede que entre los archivos hay documentos que demuestran que la reconstrucción de la vida de Gabriel fue iniciada anteriormente por la familia Bianos, concretamente en 1853 por Víctor de Bianos y su amada española Elisa de Valverde, en cuya correspondencia se encuentra un resumen del Libro de la vida de Fray Juan de Sotomayor escrita por él mismo, otra autobiografía en la que se incluye el Lazarillo..., etc. Desdoblamientos que siembran la duda acerca de la existencia histórica de Gabriel al sugerir la posibilidad de que sea un personaje inventado por estos amantes decimonónicos.

En el último capítulo León revela cuál cree que es el secreto del que Beatriz quería hacerle partícipe con su proyecto, y no es como podría parecer la identidad del autor o de los autores del Lazarillo, al respecto de lo cual León sólo dice que nada se puede afirmar con rotundidad, ya que en la reconstrucción biográfica se vislumbran indicios de prácticamente todas las teorías al respecto: el marido de Elisa es don Diego de Mendoza, el fraile acompañante es Fray Juan de Sotomayor; don Andrés también tiene en su poder una copia del Lazarillo, etcéteras.

No es éste el secreto, repetimos. El secreto según León es él mismo, quien como «fiel amante», conminado por el pacto contraído con Beatriz de finalizar el proyecto de Abel, ha pasado de ser un profesor de francés a ser un novelista, un escritor, lo que le ha permitido dar testimonio del mundo de Beatriz, del mundo de Abel y Gabriel, y con ello, de su propio mundo, lo que le inserta en la historia y paga su tributo a la posteridad 6 .

Es decir, en Como fiel amante o la invención del Lazarillo, tras un título que parece ofrecer el dispositivo de la invención de la novela moderna, se descubre la

\footnotetext{
${ }^{4}$ Cf. L. Moreno, loc. cit., pág. 26.

5 La bibliografía al respecto de la posible autoría del Lazarillo es ingente. Me limitaré a destacar dos estudios recientes: M. Agulló y Cobo, A vueltas con el autor del LAZARILLO. Con el testamento y el inventario de bienes de Don Diego Hurtado de Mendoza, Calambur, Madrid, 2010; R. Navarro Durán, Alfonso de Valdés, autor del Lazarillo de Tormes, Gredos, Madrid, 2003.

${ }^{6}$ Cf. L. Moreno, op. cit., pág. 22.
} 
experiencia de hacerse novelista, como ya hiciera Unamuno en Cómo se hace una novela? . Y es que el mismo Pageaux en la presentación, por así decir, «oficial» de su novela confiesa que en esta obra él también relata su autobiografía como novelista, su propio incardinarse en la histórica a través de la escritura8.

Dicho lo anterior, y bajo nuestro criterio, lo que subyace en toda la novela es algo tan originario como la interpretación humanística del lenguaje, de la literatura y la escritura 9 . Con la puesta en juego del problema de la autoría sobre el caso paradigmático del Lazarillo Pageaux realiza una defensa del autor como poietes, así como de la naturaleza histórica de los objetos del espíritu, lo que supone un frente de resistencia no sólo contra las posturas posmodernas neo-positivistas y neo-formalistas del lenguaje ${ }^{10}$, sino principalmente contra el descreimiento de la nueva crítica francesa de la Nouvelle derivada de la crítica barthesiana y sus proclamas de La muerte del autor ${ }^{11}$.

En la obra teórica de Alfonso Reyes encontramos quizás la reconstrucción moderna más acabada de la epistemología literaria como operación humanística. Concretamente en El deslinde ${ }^{12}$, asumido el desajuste esencial entre palabra y ente, entre psicología y lenguaje, distingue Reyes las actividades del espíritu dedicadas a salvar esa discontinuidad y sus respectivas operaciones. Así como la Ciencia trata de superar la distancia psicológica reduciendo la ambigüedad con un lenguaje unívoco, lo que le permite expresar la experiencia humana en ese ámbito de conocimiento; la Literatura la franquea en el plano de la fantasía y expresa la experiencia común del hombre, no la experiencia de un determinado orden de conocimiento, sino la experiencia pura.

Pues bien, debido precisamente a esta universalidad cualitativa inabarcable por cualquier poética particular, la literatura recurre según necesidad a las demás semánticas y poéticas a modo de fertilizaciones a fin de explotar el valor estético del lenguaje para dar significado a sus datos y ofrecer la intuición de lo infinito en términos finitos. Este uso del lenguaje combina en valor máximo

${ }^{7}$ M. de Unamuno, Cómo se hace una novela (ed. de T. Gómez Trueba), Cátedra, Madrid, 2009.

8 Presentación de la novela Como fiel amante o la invención del Lazarillo, presentación a cargo de R. García Moreno, en El Colegio Oficial de Doctores y Licenciados en Filosofía y Letras de la Comunidad de Madrid. Disponible en línea: $<$ https://www.youtube.com/watch?v=q1kgs6swGUc $>$ [consulta: 10 de agosto de 2014].

9 Véase M. D. Abascal, «La teoría humanística del lenguaje», en P. Aullón de Haro (ed.), Teoría del Humanismo, I, págs. 445-482, Verbum, Madrid, 2010.

${ }^{10}$ Para una exposición del debate narratológico, véase A. Garrido Domínguez, Narración y ficción. Literatura e invención de mundos, Iberoamericana, Madrid, 2011.

${ }^{11}$ R. Barthes, El susurro del lenguaje. Más allá de la palabra y de la escritura (trad. de C. Fernández Medrano), Paidós, Barcelona, 1994.

${ }^{12}$ A. Reyes, El deslinde. Prolegómenos a la Teoría literaria (ed. de P. Aullón de Haro y E. Zarzo), Verbum, Madrid, 2014. 
las tres notas lingüísticas (comunicativa, acústica y afectiva), con el propósito de alcanzar estilísticamente el ajuste psicológico de precisión comunicativo-expresiva; y el ajuste estético de especie lingüística, que resulta en univocidad de contenido intuitivo. No caben pues argumentos sobre colonizaciones entre géneros literarios, principalmente porque Reyes no distingue géneros, sino procedimientos de ataque de la mente literaria sobre sus objetivos.

¿Cómo opera entonces la literatura? Reyes afirma que la literatura opera por arte de ficción y universalidad. Por una parte, evoca un mínimo de realidad, no como dato sino por su valor atractivo o de significado, y lo complementa con la voluntad íntima verbalmente manifestada en un suceder irreal con carga contemplativa. Y por otra parte, capta sintéticamente lo universal humano y humaniza los contenidos al presentarlos como actos del hombre en general. Es decir, si bien es cierto que la literatura puede tomar sus elementos de la realidad, su operación no se limita a la mímesis, entendida ésta como el relato verosímil de acontecimientos exteriores al espíritu, sino que sobre tales contenidos, y desentendiéndose del suceder real, añade a lo ya existente probabilidades teóricas y motivos inventados por el espíritu. A esta construcción estética añadida e interesante por sí independientemente de su acontecer, que no arbitraria pues parte de alguna manera de un mínimo real, la denomina Reyes con término tradicional lo verísimil ${ }^{13}$. La catacresis, mentar con palabras lo que no tiene palabras, se convierte entonces en el procedimiento literario por excelencia para salvar el desajuste entre lenguaje y psicología.

Así pues, la ficción, ajustada o no al suceder real, cumple la verdad filosófica o universalidad aristotélica entendida como la verdad psicológica o expresión de las representaciones subjetivas, además de la verdad del mínimo del suceder real o verdad práctica de las operaciones mentales. La vida del objeto literario viene a consistir en un diálogo colaborativo en el que creador y receptor participan activamente en la representación de un objeto literario. Es por esto que cualquier intento de juzgar los objetos literarios desde el paradigma de la verdad como correspondencia incurre en la falacia positivista según la cual los objetos del espíritu son esencialmente idénticos a los objetos naturales. Los objetos del espíritu exigen una aproximación estética y hermenéutica, y no meramente utilitarista.

Según esta fenomenología de la intención hermenéutica la literatura en tanto operación del espíritu se caracteriza por una intención semántica referida al suceder ficticio y una intención formal relativa a la expresión estética; con lo que se sitúa en la serie temporal, acústica y subjetiva, con reflejo interior en simultaneidad de movimientos de unidades anímicas.

Ahora bien, Alfonso Reyes parte de una representación de hombre como ser expresivo $^{14}$ y de un desajuste esencial entre palabra y ente que le llevan a definir la literatura como aquella operación epistemológica capaz de salvar dicha

\footnotetext{
${ }^{13}$ Cf. A. Reyes, loc. cit., pág. 138.

${ }^{14}$ A. Reyes, La experiencia literaria, en Obras Completas, XIV, FCE, México, 1997, pág. 90.
} 
distancia intensivamente en el plano de la fantasía. No obstante, y como se ha visto en el tratamiento del lenguaje Reyes ha recuperado, a través de su mentor P. Henríquez Ureña, la idea de expresión de la tradición hispano-italiana fundada en la teoría del Barroco que Baltasar Gracián especificó en el «exprimir» o expresar de un artificio necesario para la realización simultánea de verdad/belleza capaz de construir la metáfora continuada ${ }^{15}$. Este concepto compartido con Eduardo Nicol es lo que nos permite recurrir a este autor para complementar metafísicamente el argumento de Reyes, pues, a nuestro juicio, la operación simbólica refiere en última instancia a la ontología del ser expresivo, siendo la dialéctica del ser indisociable, por no decir determinante, de la dialéctica de la expresión.

Desde un enfoque fenomenológico y primariamente apofántico Nicol sostiene en la Metafisica de la expresión ${ }^{16}$ que la forma de estar ahí del hombre consiste en un afirmarse o darse a conocer que presupone ontológica y epistemológicamente a un semejante complementario, pero irreductible, capaz de reconocerle como ser expresivo e interpretarle.

Según esta definición, el lenguaje no es el medio por el cual sujetos heterónomos se refieren a las cosas, antes bien es la comunidad dialógica la que funda a los interlocutores en un pacto existencial, pues sólo a través de la verificación del otro pueden reconocer tanto la objetividad de la realidad común, como su propia mismidad. La verdad apofántica consiste en la concordancia comunitaria tanto respecto al ser del ser comunicado como respecto del ser común.

Del mismo modo, la expresión no es una mera mediación, ni una representación, sino el darse inmediato del ser hombre, cuya individualidad se actualiza en el vínculo simbólico con su semejante, pues en cada uno de los actos de expresión están presentes no sólo el ser situacional de quien expresa y el ser del objeto intencional de la intercomunicación, sino también el ser complementario del interlocutor. En consecuencia, si el ser del hombre se da en su expresión, y ésta es un proceso de diversificación y de creciente ambigüedad que exige interpretación; el individuo, más que una identidad autónoma, es un estado hermenéutico históricamente cambiante que trasciende la individualidad y sólo es posible como pacto existencial entre entidades ontológicamente complementarias. En síntesis, la estructura común del hombre como ser del sentido es esta forma de ser expresiva, intencionalmente comunicativa, histórica, comunitaria y forzosamente diferencial.

En este orden del ser, la palabra, el logos, es tanto reproductiva como productiva, pues el hombre al convertir las cosas en objetos comunicables produce el ser significativo en tanto ser-presente-para-otro, lo que sobreañade un mundo simbólico al mundo natural indiferente ${ }^{17}$; lo verisímil definido por Reyes.

Dada entonces la naturaleza poiética del entendimiento y la diversidad de sistemas simbólicos posibles, la tarea fundamental del hombre es determinar el

\footnotetext{
${ }^{15}$ Cf. «Estudio Preliminar», en A. Reyes, El deslinde (ed. cit.), pág. XXV.

${ }^{16}$ E. Nicol, Metafísica de la expresión, FCE, México, 1989.

${ }^{17}$ Cf. E. Nicol, loc. cit., pág. 156.
} 
sistema simbólico que asume en relación al ser, el modo de atención o ethos que adopta ante la realidad. En este punto Nicol hace una clasificación general de lo que denomina «dispositivos vitales o vocacionales» según el tipo estético, pragmático o científico; todos ellos susceptibles de traducción existencial debido a su integración en el mundo global del sentido. De este modo, si bien es cierto que la posición del hombre en el cosmos es una cuestión ontológica, la incorporación a un mundo de sentido es una decisión ética. La literatura sería precisamente una de esas comunidades de sentido, una toma de postura ante la realidad.

A la luz de los anteriores principios ¿qué nos ofrece la novela de Pageaux? Siguiendo la metafísica de la expresión León Moreno se revela como un ser expresivo que establece un vínculo existencial con Beatriz, su semejante complementario, con quien entabla una relación dialéctica, que le permite en primer término, reconocerse como una mismidad histórica y dialógica; y en segundo lugar, gracias a realizar el proyecto de Abel, gracias a seguir la llamada de Abel, hacerse diferente en su acto de expresión. León Moreno ha tomado conciencia de que en su testimonio se ofrecen no sólo su singularidad y el objeto intencional, la biografía de Gabriel de Bianos; sino también el otro complementario, Beatriz; y en definitiva, su mundo de sentido común, la verdad apofántica de la comunidad humana. En una palabra, León se ha integrado vocacionalmente en un sistema simbólico distinto, en el mundo de sentido de la creación literaria.

Desde este punto de vista, los problemas metafísicos y epistemológicos de la autobiografía, como son la cuestión de la construcción de la identidad y la referencia, y el problema de la verdad y la temporalidad, quedan totalmente reformulados.

En primer lugar, la autobiografía no es el medio por el cual un sujeto identitario y ontológicamente autónomo exterioriza verbalmente su interioridad, sino su propia expresión, el acto de ser hombre, el despliegue de la serie indefinida de pactos existenciales cuya dispersión orgánica conforma la mismidad dialógica e históricamente cambiante que es el hombre.

Siguiendo esta interpretación, en nuestra novela tenemos un primer pacto existencial contraído entre Beatriz y León, en el que se manifiestan a parte del ser dialéctico común, la individualidad de León, la complementariedad de Beatriz y el objeto intencional: los legajos de Abel. Se despliegan también por un lado el contrato existencial entre Beatriz y Abel, ya que los legajos los recopilan entre ambos; por otro el de León y Abel, pues León ejecuta el proyecto de Abel; y en tercer término, el de Abel y Gabriel, pues Abel, pese a dejar inacabada la autobiografía de Gabriel, igualmente en su expresión se ofrecía él mismo como escritor, Gabriel como complementario y la realidad común: los documentos encontrados. 
Asimismo, en la autobiografía de Gabriel se revela el pacto existencial con doña Elisa, en el que se expresan la individualidad de Gabriel, la complementariedad de Elisa y el objeto intencional: el trayecto en el que redactan el Lazarillo junto a Fray Juan. Nuevamente, se despliega el pacto entre Gabriel y Fray Juan, y así sucesivamente, hasta llegar al pacto también epistolar entre Lázaro y Vuestra Merced. Pero es que también se dan pactos existenciales entre Gabriel y León, pues León sigue el proceso de aprendizaje de Gabriel, aplicando las reglas de Fray Juan para escribir su autobiografía. Por eso no es posible reducir la estructura de la novela a la caja china, porque es más bien una diseminación de mundos de sentido relacionados vocacionalmente en la que cada personaje toma la palabra para ofrecer el ser y exigir respuesta.

En segundo lugar, el propio conocimiento es temporal y hermenéutico. Nada resulta de la mera confrontación presente entre el sujeto y el objeto, no hay experiencia perceptiva sin dialéctica. La evidencia apodíctica del ser reside en el logos dialógico, expresivo y comunicativo. Únicamente si el otro verifica la mismidad, adquirirá ésta auténtica objetividad, no ya en virtud de la temporalidad subjetiva, sino de la del otro. Verificar es entonces sacar a una verdad de su aislamiento mediante la corroboración ajena. Incluso en el proceso de reflexión interior, claramente ejemplificado en las meditaciones de León Moreno, el conocimiento es temporal y dialógico, pues en él se confrontan datos temporalmente distintos respecto de una cosa, y se determina uno de los sentidos posibles siempre pendiente de lo no-dicho.

En este contexto, la autobiografía, las memorias, lo que según Nicol vendría a designar el ser acumulado en el proceso temporal de existencia ${ }^{18}$, no tiene por función posibilitar el balance del ser pasado, que siempre sería negativo por la pérdida de potencialidad de ser que conlleva, ni recuperar un mundo de sentido que ya no existe. Antes bien y dado que cada acto de expresión mantiene la actualidad de lo que fue y de lo que no fue de forma activa, el recuerdo es la actualización consciente y selectiva de algo que se ofrece en su totalidad histórica. Es decir, en el mismo proceso de expresión de León Moreno en el que se afirma diferencialmente como lector, traductor y escritor de forma indisociable, se actualizan intuitivamente en el tiempo literario cada uno de los mundos de sentido relatados.

Se puede afirmar entonces que Pageaux en La invención del Lazarillo expresa la forma común del ser hombre, ese modo de ser simbólico, dialéctico e histórico, y así lo ratifican frases como: «Tal ha sido la verdadera idea de Beatriz: transformar al insignificante catedrático en escritor» ${ }^{19}$. «De esta historia que también es novela» 20 «poco importa la verdad [...] lo importante es cumplir lo que he prometido a Beatriz» $»^{21} \mathrm{y}$ «contar otra historia que no es la

\footnotetext{
${ }^{18}$ Cf. E. Nicol, loc. cit., pág. 191.

${ }^{19}$ Cf. L. Moreno, op. cit., pág. 50.

${ }^{20}$ L. Moreno, loc. cit., pág. 157.

${ }^{21}$ L. Moreno, loc. cit., pág. 18.
} 
mía sino la que he de escribir ${ }^{22}$. Para ello, Pageaux ha recurrido a todas las poéticas necesarias para dar significado a la universalidad cualitativa inabarcable de las relaciones personales, y ha añadido algo nuevo a lo ya existente, lo verisímil. En el caso de la autoría del Lazarillo Pageaux, a través de un relato de viajes, ha articulado una expresión en la que humaniza los datos al respecto presentándolos como actos del hombre en general. Así mientras acompañamos a Gabriel en su proceso de aprendizaje, asistimos al encuentro de las principales corrientes socioculturales de la España del siglo de oro: el pensamiento cristiano representado por don Mateo, el erasmismo de Fray Juan, y el humanismo renacentista italiano de doña Elisa, y con ello, a la articulación del prototipo de la novela moderna La vida de Lazarillo de Tormes.

Aquí revela su sentido la comparación insinuada en la introducción entre la obra de Pageaux y la de Unamuno, pues a nuestro juicio, Como fiel amante se incardina vocacionalmente en el mundo de sentido de Cómo se hace una novela.

En Cómo se hace una novela Unamuno narra su autobiografía como exiliado en Francia. Autobiografía que desde el inicio define como novelesca, ya que el narrador, por el mero hecho de ser elaborado literariamente, es ya un elemento de ficción. Este Unamuno literario relata la elaboración de una novela protagonizada por U. de la Raza, un símbolo de sí mismo y de lo español en general, que comienza la lectura de un libro autobiográfico en el que se afirma que cuando el autor muera, el lector también morirá. Se trata del tópico literario que sitúa al lector ante la elección de renunciar a la lectura del libro y vivir su vida, o vivir la vida del texto y morir. Una falsa aporía que juega con la pretendida muerte del autor para desmentirla.

Cabe recordar que esta novela es redactada originalmente en castellano en 1925, inmediatamente traducida al francés por Jean Cassou y publicada en 1926. $\mathrm{Al}$ año siguiente, el mismo Unamuno retoma la versión francesa y la traduce al castellano para la edición española. Una operación de re-traducción realizada con el objetivo de restar importancia a un posible texto original, y resaltar la naturaleza de la novela como despliegue orgánico de añadidos, traducciones, re-traducciones, censuras, comentarios y reconstrucciones, pues lo importante de la novela no es ni su origen, ni su argumento sino el hacerse de la novela.

En este sentido deben interpretarse frases como: «¿Hay novela más novelesca que una autobiografía?» ${ }^{23}$. «La novela de mí [...] no es un ejemplo de ego-ismo, sino de nos-ismo [...] la hemos hecho los otros y yo» ${ }^{24}$. «La esencia de un individuo es su historia» 25 y «un modo de vivir la historia es contarla» ${ }^{26}$. De aquí que Unamuno afirme que uno no sólo es padre de su obra, sino también hijo, ya que en ella se expresa, se actualiza, revela sus entrañas de humanidad: esa convivencia de filialidad y paternidad que componen el eso

\footnotetext{
${ }^{22}$ L. Moreno, loc. cit., pág. 81.

${ }^{23}$ M. de Unamuno, op. cit., pág. 124.

${ }^{24}$ M. de Unamuno, loc. cit., pág. 139.

${ }^{25}$ M. de Unamuno, loc. cit., pág. 138.

${ }^{26}$ M. de Unamuno, loc. cit., pág. 137.
} 
anthropos, la perpetuidad que nos enlaza al pasado y al futuro, el tiempo en el que se desarrolla la obra que es nuestro espíritu27. Un razonamiento que León recupera literalmente: «Cada hombre es hijo de sus obras» ${ }^{28}$.

En definitiva, ambas novelas, Cómo se hace una novela y La invención del Lazarillo, bajo títulos que parecen prometer el engranaje de la invención de la novela, coinciden en que la novela no tiene mecanismo porque ella misma es organismo. Un organismo que no se puede explicitar más que mostrando el despliegue histórico del pacto existencial constituido en la escritura. Por eso ambas obras cuentan cómo se hace un novelista, cómo un hombre se incardina en la historia a través de la escritura, o más bien de las escrituras, de las traducciones, reconstrucciones, etcétera, en un proceso que se continúa en los lectores. Y es que contar la vida es una toma de posición ante ella, es asumirse como ser creador de sentido. Esto es lo que explica que Unamuno no termine su novela, no sólo para demostrar su infinita permeabilidad y continuidad, sino para remarcar que lo novelesco no es el argumento, sino la vida literaria que continúa en el lector. De aquí que Unamuno inste al lector a hacer su propia novela, a que se encuentre a sí mismo a través de la escritura, y entre en la historia; pues mientras se es sólo lector, como U. de la Raza, simplemente se padece la novela, y lo importante, lo que crea sentido, es hacerla.

No obstante, a nuestro parecer, Pageaux ha añadido algo distinto respecto a la obra de Unamuno. Ciertamente Unamuno se distancia de la obra al afirmar que el Unamuno literario es ya un elemento de ficción; Pageaux como autor se ha distanciado un paso más del mundo imaginario creado al ceder a León Moreno, el autor ficcionalizado, toda la responsabilidad de la enunciación. Pero he aquí el añadido de Pageaux, y es que en la solapa de la cubierta del volumen, sobre la designación de León Moreno a pie de foto, el retrato que aparece es el de Pageaux. Y ésta es la única referencia que existe en todo el volumen a su autor real. Lo cual genera un problema pragmático, pues al hacer coincidir narrador, protagonista y autor en el heterónomo León Moreno en una novela en la que, pese a la exigida suspensión del principio de credulidad, nunca se pierde de vista que se trata de una novela falsamente autobiográfica, afirma y niega simultáneamente el llamado «pacto autobiográfico»»29. ¿Cómo interpretar este giro?

En la presentación de la novela Pageaux confirma que esta obra es también su autobiografía, su propio hacerse novelista. En efecto, del mismo modo que León es capaz de distinguir los textos de Abel de los de Gabriel por cómo describen su espacio, por cómo elaboran estéticamente el paisaje, se percibe la humanización del paisaje realizada por Pageaux en recreaciones similares a las que realiza Unamuno desde la frontera. Pero más concretamente, es el propio Pageaux quien señala ese mínimo de realidad elaborado en la novela.

${ }^{27}$ M. de Unamuno, loc. cit., pág. 179.

${ }^{28}$ L. Moreno, op. cit., pág. 166.

${ }^{29} \mathrm{Ph}$. Lejeune, El pacto autobiográfico y otros estudios (trad. de A. Torrent), Megazul-Endymion, Madrid, 1994. 
Lo que él denomina su experiencia del Lazarillo en España: la contemplación de un ciego golpeando con su bastón el suelo desde la ventana del Hotel París, en su primer viaje a León en 1956. Esta experiencia aparece en la novela como la vibración estética que permite a Gabriel dar forma a la idea del Lazarillo ${ }^{30}$ y de la que destaca precisamente el ritmo; lo que ubica la literatura en la serie acústica, tal como hace Reyes.

También de forma inesperada para los lectores de la obra, Rosa García Moreno, encargada de la presentación, nos confiesa que ella cree ser el origen estético de León Moreno, como demuestra la coincidencia del apellido. A este respecto, Pageaux dice escoger los nombres de Abel, Gabriel y Víctor por un criterio meramente pragmático: mantenerse inalterables tanto en francés como en castellano. No obstante, bajo nuestro criterio, León sí tiene una intención dialéctica que es la siguiente.

A lo largo de toda la novela se diversifican y clonan espacios, personajes y manuscritos hasta neutralizar la cronología. En varias ocasiones el lector sólo tiene claro que todo empieza en León, sin saber bien en qué siglo se encuentra. $\mathrm{Y}$ es que el municipio de León es el espacio geográfico donde se origina el mundo de sentido de Beatriz, Abel y León Moreno; Beatriz muere en León; y León Moreno es el espacio en el que confluyen los mundos de sentido, cada uno de los mundos que se despliegan en la novela y el del propio Pageaux. León es una de las expresiones vocacionales desde la que se inicia el despliegue del ser dialéctico e histórico. Es un testigo de ese mundo ${ }^{31}$ capaz de actualizarlo y darle la eternidad literaria estableciendo un pacto existencial con el lector, en que ofrecerle la comunidad histórica y dialéctica que es, o mejor dicho, que son. Y así lo verifica León cuando al final de la novela dice: «Beatriz ha vuelto a aparecer [...] no es Beatriz en persona [...] es la propia substancia de mi escritura $\rangle^{32}$. Por eso en la contraportada emplea las mismas palabras que ella le dice a él para motivarle a escribir. Tras León, tras Pageaux, su mundo de sentido, no su persona particular, sino su humanidad común se actualizará y continuará desplegándose en el pacto existencial con el lector.

De vuelta al retrato. Según la metafísica de la expresión, el hombre revela su integridad en su mera presencia. El cuerpo, la individualidad óntica, no es testimonio indirecto de la presencia, la presencia es directa y total, su aquí y ahora, su particularización como hombre concreto. En consecuencia, al ofrecer un retrato, muestra el ser dialéctico e histórico que exige respuesta.

De otra parte, según Alfonso Reyes un retrato es como una autobiografía, un documento que a la vez es arte, es decir, un elemento constituido por una infinitud cualitativa de relaciones personales que lo hace únicamente abarcable por la ficción. Parafraseando a Unamuno podríamos preguntar: ¿Hay algo más novelesco que un retrato?

\footnotetext{
${ }^{30}$ L. Moreno, op. cit., pág. 87.

${ }^{31}$ L. Moreno, loc. cit., pág. 16.

32 L. Moreno, loc. cit., pág. 170.
} 
En este orden de ideas, Pageaux se ha ofrecido, ha afirmado su individualidad óntica, pero no a través de la identidad inmutable de su nombre o de su firma, que lo determinan como sujeto ontológicamente autónomo, sino que lo ha hecho a través de su mera presencia, con lo cual, lo que ha ofrecido es su mismidad dialéctica.

Sólo un último apunte respecto del título Como fiel amante. Como es habitual en la tradición literaria europea, la resonancia platónica a lo largo de toda la novela es muy evidente. Lo prueban fórmulas como la dedicatoria del Marqués de Santillana «yr donde fueres, commo fiel amante, e conseguirte, dulce mia ydea», o el constante «el secreto que quería participarme»»33, etc.

A nuestro parecer, la clave platónica del texto está, tal y como señala Nicol, en el Banquete (191d) donde tras relatar el mito de la escisión de los seres andróginos, se dice: «cada uno de nosotros es un símbolo de hombre, al haber quedado seccionado en dos de uno solo» ${ }^{34}$. Una sentencia que podría haber dado lugar a una metafísica de la expresión en el mismo origen de la filosofía occidental por entrañar el significado de que en cada acto de expresión el hombre ofrece la forma común de la humanidad. Y es que, según la metafísica de la expresión, el ser del hombre, una vez integrado vocacionalmente en un mundo de sentido, si sigue con fidelidad el ethos de ese mundo y responde a la presencia del otro con autenticidad, alcanza la libertad entendida como autarquía.

Tanto León Moreno como Gabriel de Bianos han seguido fielmente «el mandato tierno e imperioso» de su angelica donna en ese arduo proceso de «añadir algo nuevo al mundo tal como es, y revelarse a sí mismo» ${ }^{35}$. Han tomado conciencia de su ser dialéctico y se han convertido mediante la escritura en amantes más sensatos. Ambos han creado sentido, y por tanto, libertad. En términos platónicos, el hombre arrastrado, no por la hybris sino por la sophrosine y el divino eros, o como diría Reyes no por la emoción poética como estado subjetivo sino por el verbo poético, participa de la realidad más auténtica, del ser común.

Podemos concluir que Como fiel amante o la invención del Lazarillo es un ejercicio literario en el cual, a través de la puesta en juego del problema de la autoría, se desmiente la proclama barthesiana de la muerte del autor, reafirmando al autor como un auténtico poietes.

En esta novela, aun desplazada la autoría hasta la incertidumbre homérica, y asumido que todo texto es una reconstrucción de múltiples escrituras, siempre hay un responsable, el lenguaje siempre es expresión de la humanidad. El Autor nunca es meramente el que escribe, ni es el pasado del texto, ni puede identificarse con su firma o su prestigio. No se trata por tanto de bascular la importancia del Autor al lector y proclamar la muerte del autor para que el lector viva, pues esta escisión es falaz. La escritura no destruye el origen, antes bien es la expresión del pacto existencial que funda tanto al autor como al lector.

${ }^{33}$ Cf. L. Moreno, loc. cit., pág. 170.

34 Platón, Banquete, en Diálogos, III (trad. de C. García Gual, M. Martínez Hernández y E. Lledó Íñigo), Gredos, Madrid, 1988, pág. 226.

35 L. Moreno, op. cit., pág. 145. 
En suma, en Como fiel amante o la invención del Lazarillo Pageaux se propone recuperar un sentido humanístico clásico para la autobiografía contemporánea en un contexto marcado por el escepticismo acerca de la capacidad de expresar la vida interior. El escepticismo desaparece cuando se asume que en la autobiografía no se afirma una identidad ontológicamente autónoma, «no son confesiones ni memorias [...] tampoco es la crónica de una vida» ${ }^{36}$. Lo que se expresa es el ser dialéctico, la mismidad histórica. Un ser poiético cuya responsabilidad ontológica consiste en dilucidar su vocación, tomar posesión de su posición en un mundo de sentido y crear más sentido activando la comunidad histórica que es el hombre.

\footnotetext{
${ }^{36}$ L. Moreno, loc. cit., pág. 22.
} 